\title{
New Spectrophotometric Methods for the Determination of p-Aminosalicylic Acid in Tablets
}

\author{
MGH Laghari*, Y Darwis and AH Memon \\ School of Pharmaceutical Sciences, University Sains Malaysia, 11800, Penang, Malaysia
}

${ }^{*}$ For correspondence: Email: fairy_rose25@yahoo.com; Tel: +601124055956

Received: 9 September 2013

Revised accepted: 30 April 2014

\begin{abstract}
Purpose: To develop a new spectrophotometric method with improved sensitivity and at higher wavelength for the determination of $p$-aminosalicylic acid in tablets.

Methods: Two simple and sensitive spectrophotometric methods (methods $A$ and $B$ ) were developed using p-dimethylaminobenzaldehyde (DAB), and p-dimethylaminocinnamaldehyde (DAC) as derivatizing reagents for the determination of $p$-aminosalicylic acid (PAS) in tablets. The derivatization was carried out using $3 \mathrm{M} \mathrm{HCl}-\mathrm{KCl}$ buffer for DAB and $5 \mathrm{M} \mathrm{HCl}-\mathrm{KCl}$ buffer solutions.

Result: The new derivatives of PAS absorbed maximally with bathochromic shift to 460 and $555 \mathrm{~nm}$ in the linear concentration range of $0.4-2.0 \mu \mathrm{g} / \mathrm{mL}$ with molar absorptivities of $2.4 \times 10^{4}$ and $3.8 \times 10^{4}$ $\mathrm{L} / \mathrm{mole} / \mathrm{cm}$, respectively, compared to pure PAS which absorbed at $\lambda_{\max }$ of $264 \mathrm{~nm}$ with molar absorptivity $7.65 \times 10^{3} \mathrm{~L} / \mathrm{mole} / \mathrm{cm}$ in the linear concentration range of $2-10 \mu \mathrm{g} / \mathrm{mL}$. The developed methods were successfully applied to assay PAS in tablets with \% recovery of $97.6 \pm 1.71$ and $98.4 \pm$ 1.45 for methods $A$ and $B$, respectively.

Conclusion: Both PAS derivatives absorb in the visible spectral region. The presence of excipients in pharmaceutical preparations did not interfere in the determination of PAS as PAS-DAB and PAS-DAC derivatives. Both methods can be applied to determine PAS from bulk and various pharmaceutical dosage forms.
\end{abstract}

Keywords: p-Aminosalicylic acid, p-dimethylaminobenzaldehyde, p-dimethylaminocinnamaldehyde, Spectrophotometry

Tropical Journal of Pharmaceutical Research is indexed by Science Citation Index (SciSearch), Scopus, International Pharmaceutical Abstract, Chemical Abstracts, Embase, Index Copernicus, EBSCO, African Index Medicus, JournalSeek, Journal Citation Reports/Science Edition, Directory of Open Access Journals (DOAJ), African Journal Online, Bioline International, Open-J-Gate and Pharmacy Abstracts

\section{INTRODUCTION}

p-aminosalicylic acid (PAS) or 4-amino-2hydroxybenzoic acid is an anti-tubercular drug and is also used in the treatment of ulcerative colitis [1]. The review of literature reported only a few spectrophotometric [2,3], fluorometric [4], flow injection analysis [5], thin layer chromatography (TLC) [6], high performance liquid chromatography (HPLC) [7,8], nuclear magnetic resonance (NMR) [9], titrimetric [10], polarographic [11], micro-dialysis [12], radioimmune assay [13], capillary electrophoretic
[14] and ion exchange chromatographic [15] techniques for the quantitative estimation of PAS in bulk, pharmaceutical formulations and in biological samples. In view of the above fact, some simple analytical methods are in need for its quantitative estimation.

Lianidou et al [4] used benzoyl-L-tyrosylPABA/PAS test. PAS was measured as a ternary complex with terbium and EDTA. A fluorescent compound was obtained with absorption at 324 $\mathrm{nm}$. The apparent molar absorptivity of complex has not been mentioned and Beer's law was 
obeyed over the range $1-6 \mu \mathrm{g} / \mathrm{mL}$. Blake et al [15] determined PAS concentration $5-18 \mathrm{mg} / \mathrm{mL}$ using ion exchange chromatography and Vetuschi et al [2] determined PAS $10-40 \mu \mathrm{g} / \mathrm{mL}$. The present study has been carried out to develop new methods for the determination of PAS by reacting with $p$ dimethylaminobenzaldehyde (DAB), and $p$ dimethylaminocinnamaldehyde (DAC) reagents with improved molar absorptivities of $2.4 \times 10^{4}$ and $3.8 \times 10^{4} \mathrm{~L} / \mathrm{mole} / \mathrm{cm}$ than above reported methods. Further in this study the new derivatives of PAS absorb maximally with bathochromic shift to 460 and $555 \mathrm{~nm}$ with concentration range $0.4-2.0 \mu \mathrm{g} / \mathrm{mL}$ as compared to already reported methods.

\section{EXPERIMENTAL}

\section{Instrumentation}

Double beam spectrophotometer (UV/Visible spectrometer (Lambda 25, Perkin-Elmer, USA) with dual silica $1 \mathrm{~cm}$ cuvettes was used for absorbance measurements. The spectrophotometer was controlled by A computer with UVWinLab 25 software. The $\mathrm{pH}$ of various buffers was monitored using a $\mathrm{pH}$ meter (Schot Instrument Lab 850, Germany).

\section{Materials and reagents}

All the chemicals and reagents used were of analytical or pharmaceutical grades. The double distilled water used throughout the study was obtained from distillation plant all made of glass. Pure $\rho$-aminosalicylic acid (PAS), $\rho$ dimethylaminocinnamaldehyde (DAC) and sodium acetate were obtained from Fluka (Switzerland). $\rho$-dimethylaminobenzaldehyde (DAB), Acetic acid and ethanol were purchased from E. Merck, (Germany). Buffer solutions between $\mathrm{pH}$ 0.5-10 at unit internal were prepared from the solution of (1-6 M) hydrochloric acidpotassium chloride $(\mathrm{pH} 1-2)$, acetic acid-sodium acetate ( $\mathrm{pH} 3-7)$, sodium bicarbonate-sodium carbonate $(\mathrm{pH} 8-9)$ and ammonium chloride and ammonia solution ( $\mathrm{pH} 10-11)$.

\section{Method A}

1. DAB (2\%) was prepared by dissolving $2 \mathrm{~g}$ of DAB in $100 \mathrm{~mL}$ of ethanol.

2. $\mathrm{pH} 0.5(3 \mathrm{M} \mathrm{HCl}-\mathrm{KCl})$.

\section{Method B}

1. DAC ( $2 \%$ ) was prepared by dissolving $2 \mathrm{~g}$ of DAC in $100 \mathrm{~mL}$ of ethanol.
2. $\mathrm{pH} 0.5(5 \mathrm{M} \mathrm{HCl}-\mathrm{KCl})$.

\section{Preparation of standard and sample solution}

Accurately weighed $0.01 \mathrm{~g}$ of PAS was dissolved in $100 \mathrm{~mL}$ of water. The final concentration was brought to $5 \mu \mathrm{g} / \mathrm{mL}$ of PAS for both methods A and $\mathrm{B}$.

\section{Assay procedures}

\section{Method A}

Aliquots of standard drug solution ranging from 0.4 - $2 \mathrm{~mL}$ PAS solution $(5 \mu \mathrm{g} / \mathrm{mL})$ were taken separately into $5 \mathrm{~mL}$ volumetric flasks and then ethanolic solution of DAB (2\%) was added followed by $0.5 \mathrm{~mL}$ buffer of $\mathrm{pH} 0.5(3 \mathrm{M} \mathrm{HCl}-$ $\mathrm{KCl})$. The solutions were finally made up to the mark with distilled water and kept at room temperature $\left(25^{\circ} \mathrm{C}\right)$ for $5 \mathrm{~min}$. The absorbance of the solution was measured at $\lambda_{\max } 460 \mathrm{~nm}$ against the corresponding reagent blank. The amount of PAS was computed from the linear regression equation.

\section{Method B}

Aliquots of standard drug solution ranging from $0.4-2 \mathrm{~mL}$ of PAS $(5 \mu \mathrm{g} / \mathrm{mL})$ were transferred to a series of $5 \mathrm{~mL}$ calibrated volumetric flasks. To each volumetric flask, $1 \mathrm{~mL}$ of DAC (2\% ethanolic) and $0.5 \mathrm{~mL}$ of buffer $\mathrm{pH} 0.5(5 \mathrm{M} \mathrm{HCl}-$ $\mathrm{KCl}$ ) were added and then kept aside for $30 \mathrm{~min}$ at room temperature $\left(25^{\circ} \mathrm{C}\right)$. The solutions were then finally made up to the mark with ethanol and the absorbance of the solution was measured at $\lambda_{\max } 555 \mathrm{~nm}$ against the corresponding reagent blank. The amount of PAS was computed from the Beer's Lambert's plot.

\section{Assay PAS in tablets}

Ten tablets of two products from different pharmaceutical companies were collected for the analysis of PAS. An accurately weighed amount of tablets equivalent to $0.01 \mathrm{~g}$ of PAS for each preparation namely PASK (Akrikhin Pharmaceuticals - Moscow, Russia) and PAS (Star Laboratories (PVT). LTD., Lahore, Pakistan), was dissolved in the $100 \mathrm{~mL}$ volumetric flask containing sufficient volume of distilled water by shaking well and then filtered through Whatman No. 1 filter paper before adjusting to the final volume $(100 \mathrm{~mL})$ with water. This solution was considered as the stock solution. Convenient aliquots of stock solution were taken for the determination of PAS and the procedures were repeated as described for methods $A$ and $B$. 
The effect of adding $0.5-2.0 \mathrm{~mL}$ of DAB and DAC (2\% ethanolic) reagent solutions with an intervals of $0.5 \mathrm{~mL}$ were examined on absorbance of $0.8 \mu \mathrm{g} / \mathrm{mL}$ PAS $(5 \mu \mathrm{g} / \mathrm{mL})$. The absorbance was measured at $\lambda_{\max } 460$ and 555 $\mathrm{nm}$, respectively. Same absorbance was observed with addition of $1.5 \mathrm{~mL}$ and above for $\mathrm{DAB}$ and $1 \mathrm{~mL}$ and above for DAC.

The effect of time on the formation of derivatives in terms of absorbance of $1.2 \mu \mathrm{g} / \mathrm{mL}$ PAS solution in the presence of $2 \%$ ethanolic DAB and DAC solutions was examined at 460 and $555 \mathrm{~nm}$ from 0-30 min with an interval of $5 \mathrm{~min}$ at $60-90{ }^{\circ} \mathrm{C}$ in a water bath. The absorbance of both derivatization procedures was also measured at room temperature $\left(25^{\circ} \mathrm{C}\right)$ from 0 $30 \mathrm{~min}$ at an interval of $5 \mathrm{~min}$.

\section{Statistical analysis}

Paired t-test was applied to compare the mean values of analysis of pharmaceutical preparation with labeled values at $95 \%$ confidence level. Student t-test was applied to calculate confidence interval at $95 \%$ for the analyzed drug. Statistical calculations were carried out using SPSS 16.0 software package.

\section{RESULTS}

$\rho$-Aminosalicylic acid (PAS) or 4-amino-2hydroxybenzoic acid reacts with $D A B$ and DAC to form an azomethine derivatives 4-[(3Dimethylamino-benzylidene)-amino]-2-hydroxybenzoic acid (PAS-DAB) and 4-[3-(4Dimethylamino-phenyl)-allylideneamino]-2hydroxy-benzoic acid (PAS-DAC), respectively (Figure 1). The molar absorptivity of pure PAS was calculated as $7.65 \times 10^{3} \mathrm{~L} / \mathrm{mole} / \mathrm{cm}$ at $\lambda_{\max }$ $264 \mathrm{~nm}$ and obeyed the Beer's law within $2-10$ $\mu \mathrm{g} / \mathrm{mL}$. The method $A$ is based on the reaction of PAS with $\rho$-dimethylaminobenzaldehyde (DAB). The molar absorptivity of resulting colored chromogen was calculated as $2.4 \times 10^{4}$ $\mathrm{L} / \mathrm{mole} / \mathrm{cm}$ at $\lambda_{\max } 460 \mathrm{~nm}$. Method $B$ is based on the reaction of PAS with $\rho$ dimethylaminocinnamaldehyde (DAC) to form a colored solution with molar absorptivity of $3.8 \times$ $10^{4} \mathrm{~L} / \mathrm{mole} / \mathrm{cm}$ at $\lambda_{\max } 555 \mathrm{~nm}$. Beer's law was obeyed in the concentration range of $0.4-2.0$ $\mu \mathrm{g} / \mathrm{mL}$ for both methods.

The maximum absorbance of PAS-DAB and PAS-DAC derivatives were observed at $0.5 \mathrm{~mL}$ buffer $\mathrm{pH} 0.5$ of $3 \mathrm{M} \mathrm{HCl}-\mathrm{KCl}$ for $\mathrm{DAB}$ and $5 \mathrm{M}$ $\mathrm{HCl}-\mathrm{KCl}$ for DAC, respectively (Figure 4).

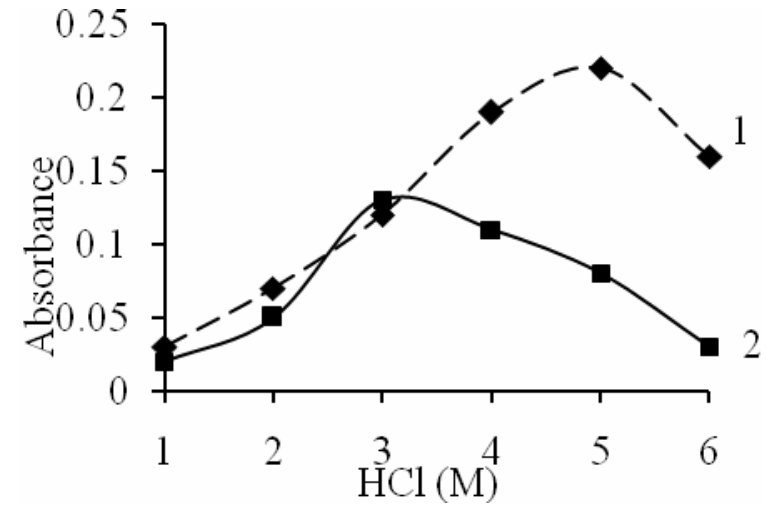

1. PAS-DAB, 2. PAS-DAC

Figure 4: Optimization of $\mathrm{pH}$

The effect of possible presence of different pharmaceutical additives such as sodium chloride, mannitol, sorbitol, lactose, sucrose, glucose, galactose and fructose was investigated at 10 times the concentration of PAS and it was observed that none of these substances interfered when the absorbance was changed within $\pm 4 \%$.

The absorbances of the solutions were measured at different time interval after formation of derivatives. There was no significant change in absorbance was observed for both PAS-DAB and PAS-DAC derivatives with relative error within $\pm 4 \%$ and the solutions were stable for more than $24 \mathrm{~h}$ at $25^{\circ} \mathrm{C}$.

Maximum absorbance was achieved at $264 \mathrm{~nm}$ for pure PAS and at $460 \mathrm{~nm}$ and $555 \mathrm{~nm}$ for PAS-DAB and PAS-DAC derivatives, respectively, against reagent blank. These wavelengths were selected as optimum for both derivatives (Figure 2).

Therefore, the addition of $1.5 \mathrm{~mL}$ of $\mathrm{DAB}$ and 1 $\mathrm{mL}$ of DAC solutions was selected (Figure 3 ).

The order of adding reagents during derivatization process played an important role in the accuracy of results and enhancement of absorbance. It was observed that the addition of $0.5 \mathrm{~mL}$ buffer $(\mathrm{pH} 0.5$ of $3 \mathrm{M} \mathrm{HCl}-\mathrm{KCl}$ for DAB and $5 \mathrm{M} \mathrm{HCl}-\mathrm{KCl}$ for DAC to PAS solution $(0.8$ $\mathrm{mL}$ ) followed by the DAB and DAC reagent (ethanolic, $2 \%$ ) resulted in a decrease in absorbance value. Taking the reagent first and then adding the buffer, followed by PAS solution also decreased the absorbance value. Maximum absorbance value was observed when optimum 


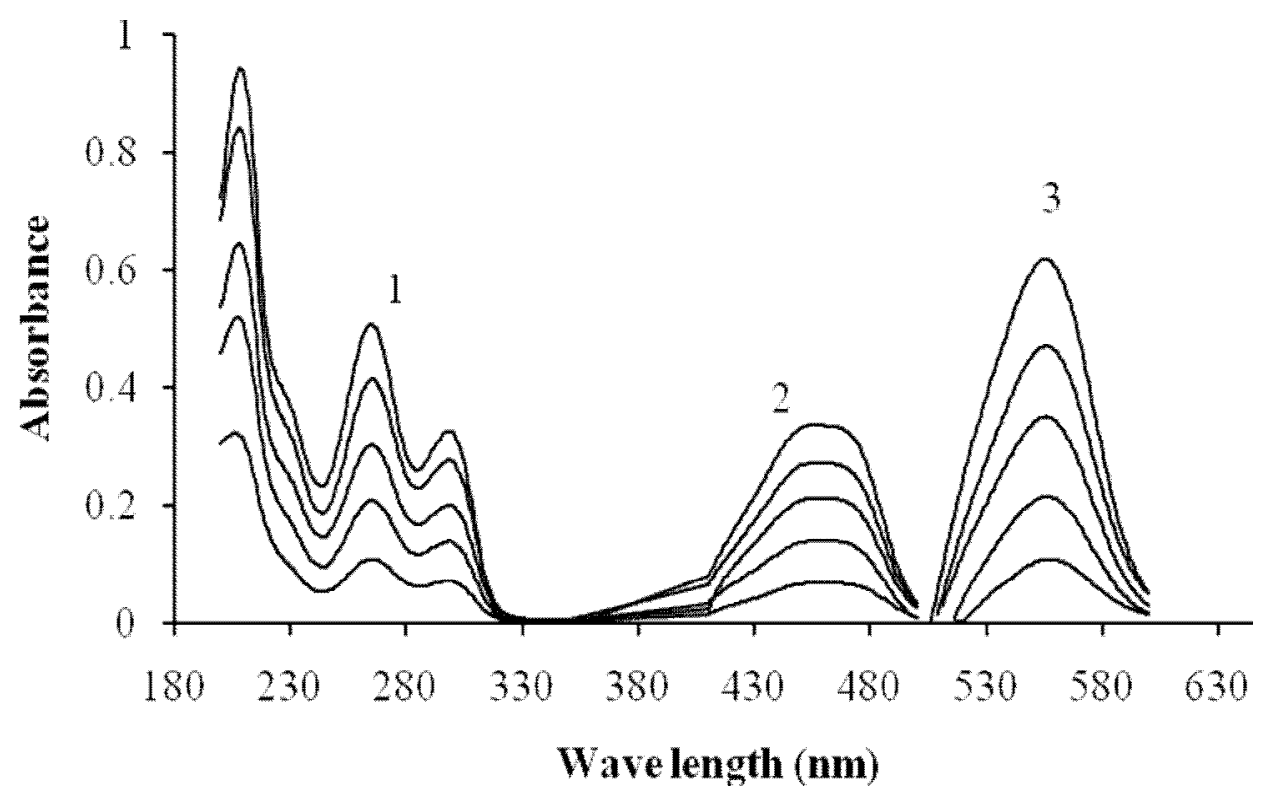

Figure 2: Optimization of analytical wavelength. Note: 1 = pure PAS $(264 \mathrm{~nm}) ; 2$ = PASDAB (460 nm); 3 = PAS-DAC $(555 \mathrm{~nm})$

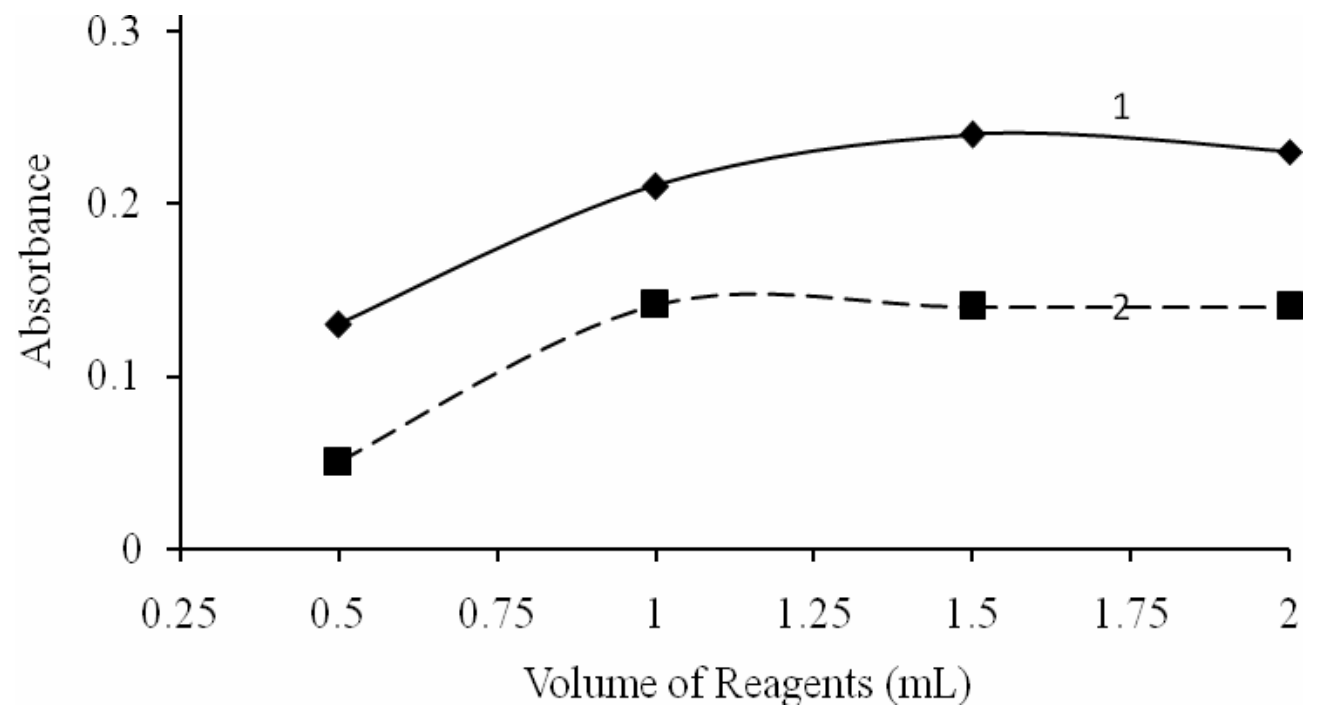

Figure 3: Optimization of volume of reagents (1 = DAB, 2 = DAC)

volumes of $\mathrm{DAB}$ and $\mathrm{DAC}$ were added to the aliquots of PAS, followed by $0.5 \mathrm{~mL}$ buffer $(\mathrm{pH}$ 0.5 of $3 \mathrm{M} \mathrm{HCl}-\mathrm{KCl}$ for $\mathrm{DAB}$ and $5 \mathrm{M} \mathrm{HCl}-\mathrm{KCl}$ for $\mathrm{DAC}$. The contents were then kept aside at room temperature $\left(25^{\circ} \mathrm{C}\right)$ for 0 and $30 \mathrm{~min}$ and the volumes adjusted to $5 \mathrm{~mL}$ with water and ethanol.

\section{Calibration plots}

The effect of variation in the concentration of PAS on its absorbance was studied. The linear calibration curves were obtained which obeyed the Beer's law within the concentration range 0.4
- $2.0 \mu \mathrm{g} / \mathrm{mL}$ of PAS with coefficient of determination $\left(R^{2}\right)$ of 0.9997 for both methods $A$ and $B$. Sandell's sensitivity $(A=0.004)$ was observed at 0.03 and $0.015 \mu \mathrm{g} / \mathrm{mL}$ for PAS-DAB and PAS-DAC derivatives, respectively. The validity of the calibration curves was obtained by the analysis of test solutions of PAS $(n=5)$ and $\%$ relative error was \pm 0.97 . Recovery, calculated by standard addition technique, was within the range $98-100 \%$ with RSD of 1.7 and $1.4 \%$ for methods $A$ and $B$. The tablets containing PAS available in the local market were analyzed to determine the amount of PAS quantitatively. The mean values $(\mathrm{g})$ and range of \% error (95\% 
Table 1: Optical characteristics

\begin{tabular}{lll}
\hline Parameter & \multicolumn{1}{l}{ Method } & \\
\cline { 2 - 3 } & $\mathbf{a}^{*}$ & $\mathbf{b}^{*}$ \\
\hline Beer's law limits $(\mu \mathrm{g} / \mathrm{mL})$ & $0.4-2.0$ & $0.4-2.0$ \\
$\lambda_{\max }(\mathrm{nm})$. & 460 & 555 \\
Molar absorptivity $(\mathrm{L} / \mathrm{mol} / \mathrm{cm})$ & $2.4 \times 10^{4}$ & $3.8 \times 10^{4}$ \\
Sandell's sensitivity $(\mu \mathrm{g} / \mathrm{mL}$ at 0.004 absorbance unit) & 0.03 & 0.015 \\
Regression equation $(\mathrm{y})^{\mathrm{a}}$ & & \\
Intercept $(\mathrm{a})$ & 0 & 0 \\
Slope $(\mathrm{b})$ & 0.1644 & 0.2877 \\
Coefficient of determination & 0.9997 & 0.9997 \\
Relative standard deviation $( \pm \%) 1 \mathrm{~g}$ & 0.03 & 0.023 \\
Relative standard deviation $( \pm \%) 0.5 \mathrm{~g}$ & 0.69 & 0.11 \\
Relative deviation $( \pm \%) 1 \mathrm{~g}$ & 2 & 1 \\
Relative deviation $( \pm \%) 0.5 \mathrm{~g}$ & 1 & 0.1 \\
Mean value, $1 \mathrm{~g} /$ tablet \pm range of error \% at $95 \%$ confidence limit & $0.98 \pm 0.94$ & $0.99 \pm 0.46$ \\
Mean value, $0.5 \mathrm{~g} /$ tablet \pm range of error \% at $95 \%$ confidence limit & $0.49 \pm 0.97$ & $0.499 \pm 0.58$ \\
\hline
\end{tabular}
$a^{*}=$ PAS-DAB, $b^{*}=$ PAS-DAC

Table 2: Intra- and inter-day accuracy and precision of PAS-DAB and PAS-DAC

\begin{tabular}{lcccc}
\hline Day & \multicolumn{2}{c}{ Absorbance (士\%RSD) } & \multicolumn{2}{c}{ \% Relative error } \\
\cline { 2 - 5 } & $\mathbf{a}^{*}$ & $\mathbf{b}^{*}$ & $\mathbf{a}^{*}$ & $\mathbf{b}^{*}$ \\
\hline Inter-day & $0.13(0.2)$ & $0.22(1.0)$ & -1.2 & 0.5 \\
Intra-day & $0.14(2.8)$ & $0.24(0.3)$ & 2 & 0.8 \\
\hline
\end{tabular}

$\mathrm{RSD}=$ relative standard deviation; $\mathrm{a}^{*}=$ PAS-DAB; $\mathrm{b}^{*}=$ PAS-DAC

confidence limit) of PAS tablets was $0.49 \pm 0.97$ and $0.99 \pm 0.46$, respectively (Table 1 ) and no significant difference in the absorbance of PAS derivatives was found at $95 \%$ confidence limit, compared with labeled value.

\section{Inter-day reproducibility/repeatability}

For the determination of intraday and inter-day reproducibility of the methods, the aqueous standard solution $(0.8 \mathrm{~mL})$ of $5 \mu \mathrm{g} / \mathrm{mL}$ PAS solution was taken in three different calibrated volumetric flasks $(5 \mathrm{~mL})$ and the procedures were followed as described in assay procedures. The absorbances were measured against reagent blank at 460 and $555 \mathrm{~nm}$. The above procedures were repeated for three days $(n=3)$. The mean absorbance of intraday and interday reproducibilities for PAS-DAB was 0.14 and 0.13 , respectively, whereas for PAS-DAC, the values were 0.24 and 0.22 , respectively (Table 2 ).

\section{DISCUSSION}

Different parameters including effects of $\mathrm{pH}$, amount of reagents added, heating time, temperature and solvents on the formation of
PAS-DAB and PAS-DAC derivatives were thoroughly studied.

In each spectrophotometric quantization, the $\lambda_{\max }$ has a profound position, so it is important that pure analyte (PAS) and derivatizing reagents (DAB and DAC) should not absorb light near the region where the analyte derivatives absorb. This may cause error in the absorption of the drug because the derivatizing reagents are added in excess to complete the reactions quantitatively. To get rid of this problem, the wavelength must be selected where the derivatizing reagent show least absorbance and the analyte derivative indicates optimum absorbance value.

The maximum absorbance of colored chromogens was observed after keeping PAS derivatives at room temperature $\left(25^{\circ} \mathrm{C}\right)$ for 0 $30 \mathrm{~min}$. Heating caused the absorbance of relevant derivatives to decrease. Therefore, heating was avoided for both PAS derivatives.

Water and ethanol were found to be the best among the solvents studied because these produced maximum absorbance and stability of PAS-DAB and PAS-DAC derivatives. 


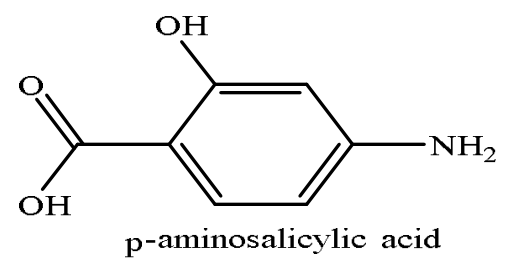

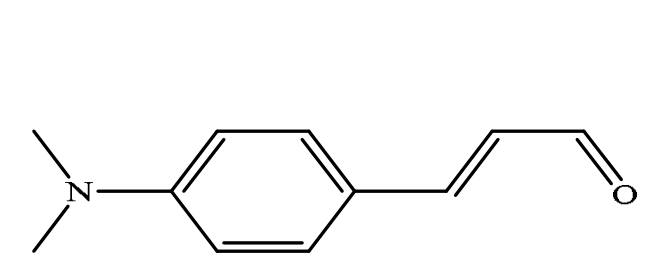

p-dimethylaminocinnamaldehyde
$+$

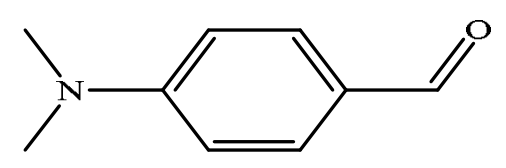

p-dimethylaminobenzaldehyde

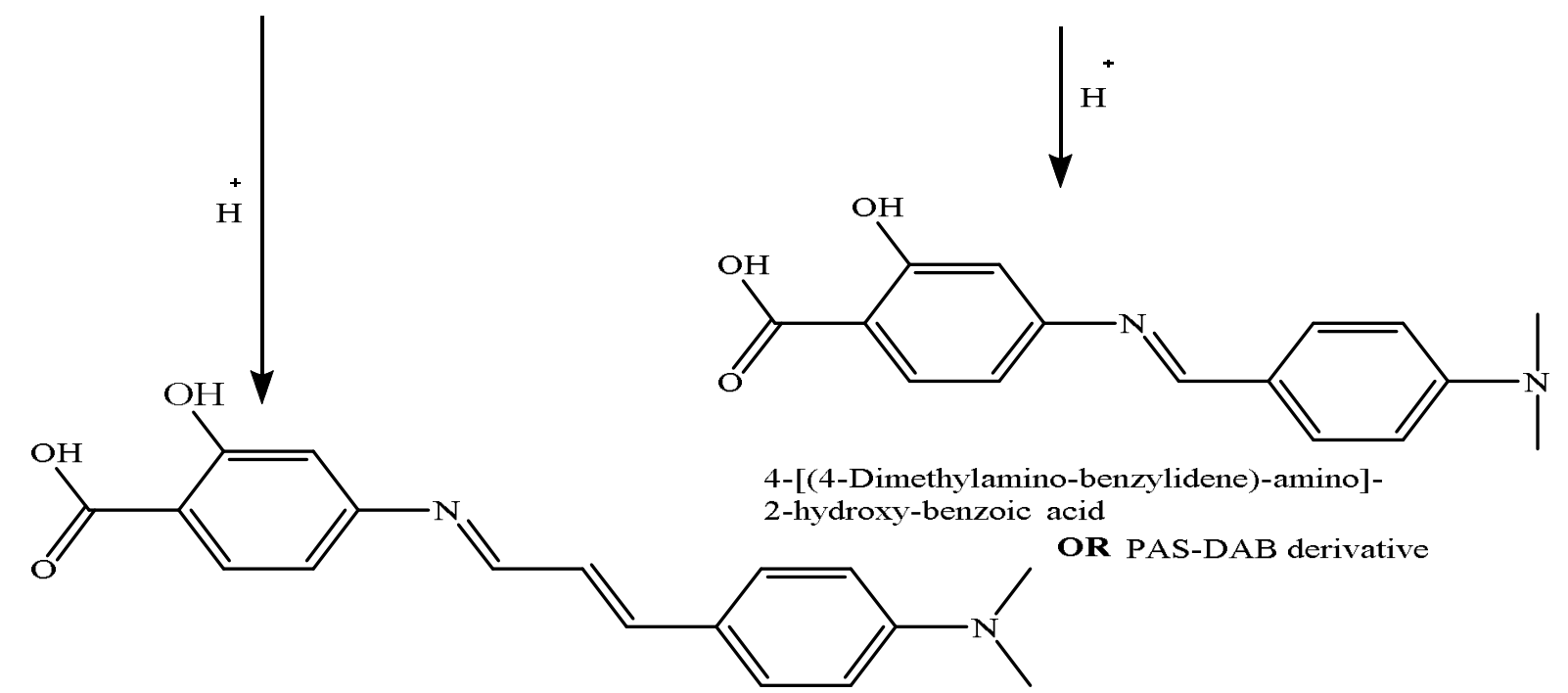

4-[3-(4-Dimethylamino-phenyl)-allylideneamino]-

2-hydroxy-benzoic acid

\section{OR}

PAS-DAC derivative

Figure 1: Formation of PAS-DAB and PAS-DAC derivatives using DAB and DAC as derivatizing reagents

\section{CONCLUSION}

The methods are free from the interferences of associated materials which may absorb in the UV region. The developed methods are simpler, and more sensitive and cost-effective than a previously reported spectrofluorometric method [4]. The methods are suitable for the determination of PAS in tablets.

\section{ACKNOWLEDGEMENT}

The authors would like to thank Universiti Sains Malaysia, Penang, Malaysia for providing financial support for this work.

\section{REFERENCES}

1. Jyoti R, Prateek KJ, Ravichandran V, Agrawal RK. Synthesis and evaluation of mutual prodrugs of isoniazid, p-amino salicylic acid and ethambutol. Arkivoc 2007; 1: 105-118.

2. Vetuschi C, Ragno G, Mazzeo P. Determination of $p$ aminosalicylic acid and $m$-aminophenol by derivative UV-spectrophotometry. J Pharm Biomed Anal. 1988; 6(4): 383-391.

3. Mouayed QA, Al-Ghabsha TS, Salih ES. Application of promethazine hydrochloride as a chromogenic reagent for the spectrophotometric determination of aniline and its substituents. Microchem 1990; 41(1): 64-71.

4. Lianidou ES, Ioannou PC. Simple spectrofluorometric determination of $p$-aminobenzoic and p-aminosalicylic 
acids in biological fluids by use of terbium-sensitized luminescence. Clin Chem 1996; 42(10): 1659-1665.

5. Evgen'ev MI, Garmonov SY, Shakirova LS. Selective determination of 4-aminobenzoic and 4-aminosalicylic acid derivatives in mixtures by flow-injection analysis. J Anal Chem 2000; 55(7): 696-702.

6. Lepri L, Desideri PG, Heimler D. Reversed-phase and soap thin-layer chromatography of aliphatic monoand polyamines. J Chromatogr 1979; 173(1): 119126.

7. Miroshnichenko II, Sokolova GB, Mokhireva LV. Clinical pharmacokinetics of para-aminosalicylic acid tablets. Antibiot Chemother 2009; 54(1-2): 20-24.

8. Hong $L$, Jiang $W$, Zheng $W$, Zeng S. HPLC analysis of para-aminosalicylic acid and its metabolite in plasma, cerebrospinal fluid and brain tissues. J Pharma Biomed Anal 2011; 54(5): 110-119.

9. Rajesh Y, Mahatma OP, Rathore DS. Application of 2Hydroxyethyl Methacrylate Polymer in Controlled Release of 4-Aminosalicylic Acid: A Colon Targeted Prodrug Approach. Inter J Chem Environ Pharma Res 2010; 1(2): 103-110.
10. Parkash R, Bala R, Lal SR. DCTA Titration of iron (III) with $p$-aminosalicylic acid and sodium azide as indicators. Talanta 1979; 26(7): 575-578.

11. Reynolds PD, Middleton SJ, Shorthouse M, Hunter JO. The effects of aminosalicylic acid derivatives on nitric oxide in a cell-free system. Alimen Pharmacol Ther 1995; 9(5): 491-495.

12. Yeping Z, Xiaozhong L, Craig EL. Comparison of recovery and delivery in vitro for calibration of microdialysis probes. Anal Chimi Acta 1995; 316(3): 403-410.

13. Shucai W, Langlai X, Guojing L, Puyan C, Kai X, Xie Z. An ELISA for the determination of salicylic acid in plants using a monoclonal antibody. Plant Sci 2002; 162(4): 529-535.

14. Zhang $X$, Xuan $Y$, Sun $A, \operatorname{Lv} Y$, Hou X. Simultaneous determination of isoniazid and p-aminosalicylic acid by capillary electrophoresis using chemiluminescence detection. Luminescence, 2009; 24(4): 243-249.

15. Blake MI, Makris K, Hunt J. Determination of sodium paminosalicylate in the presence of $m$-aminophenol. $J$ Pharm Sci 1971; 60(11): 1694-1695. 